\title{
El trabajo sexual desde una perspectiva de los derechos humanos: implicaciones del VIH/sida e infecciones de transmisión sexual*
}

\author{
Sex work from a human rights perspective: implications of \\ HIV/AIDS and sex transmitted infections
}

Recibido: 23 de abril de 2014 - Revisado: 05 de agosto de 2014 - Aceptado: 06 de noviembre de 2014

Misael Tirado Acero**

\section{Resumen}

En el trabajo sexual, se asumen constantes riesgos como las infecciones de transmisión sexual (ITS) y el virus de inmunodeficiencia humana (VIH). Este trabajo es un oficio discriminado por su contenido sexual y se ha descrito desde diversos discursos científicos y jurídicos, que han instituido una distorsión de las contingencias que allí se corren, legitimando la estigmatización de quienes se dedican a este trabajo. Por lo anterior, se requiere de políticas integrales encaminadas a prevenir, tratar, atender y apoyar el problema de las ITS y el VIH, asumiendo una visión integral en la que prevalezcan los derechos humanos como principio.

\section{Palabras clave}

Derechos humanos, trabajo sexual, estigmatización, discriminación, infecciones de transmisión sexual, virus de inmunodeficiencia humana.

\begin{abstract}
In sex work, constant risks such as sexually transmitted infections (STIs) and human immunodeficiency virus (HIV) are assumed. This work is a profession discriminated against because of its sexual content and described from various scientific and legal discourses, which have instituted a distortion of the contingencies that are run there, legitimizing the stigmatization of those engaged in this work. Therefore, it requires comprehensive policies to prevent, treat, care for and support the problem of STIs and HIV, taking a holistic view on the prevailing human rights as a principle.
\end{abstract}

\section{Keywords}

Human rights, sex work, stigmatization, discrimination, sexually transmitted infections, human immunodeficiency virus.

\footnotetext{
${ }^{*}$ El presente artículo de reflexión es resultado de la investigación "Dinámicas del comercio sexual en Bogotá Colombia", en el periodo 2013-2014, como corolario a la tesis doctoral de Sociología Jurídica e Instituciones Políticas de la Facultad de Derecho de la Universidad Externado de Colombia. Se circunscribe a los Grupos de Investigación: Conflicto y Criminalidad-Derecho Penal y Derecho Público, de la Facultad de Derecho de la Universidad Católica de Colombia, Bogotá. Colombia.

** Sociólogo por la Universidad Nacional de Colombia, con posgrados en Economía y Evaluación Social de Proyectos por la Universidad de los Andes. Doctor en Sociología Jurídica e Instituciones Políticas por la Universidad Externado de Colombia. Posdoctor en Derecho por la Universidad de Buenos Aires (en curso). Profesor e investigador en facultades de derecho (pregrado y posgrado) de la Universidad Nacional de Colombia, Universidad Santo Tomás, Universidad Militar Nueva Granada, Universidad La Gran Colombia, Escuela de Investigación Criminal, Universidad Externado de Colombia (Facultad de Administración de Empresas), Bogotá, Colombia, entre otras. Docente visitante en universidades de Argentina, Chile, Brasil, Perú, Panamá y Estados Unidos. Consultor Naciones Unidas y Presidencia de la República. Investigador social con amplia experiencia de trabajo de campo desde la perspectiva de juventudes, género $\mathrm{y}$ poblaciones en alto riesgo, incluyendo comunidades urbanas y rurales en situación de conflicto, laborando tanto en atención como en prevención en el tema de derechos humanos y políticas públicas.

Correo electrónico: misaeltirado@gmail.com; misaeltirado@fundacionfefsa.org
} 
Independientemente de la condición legal del trabajo sexual, siempre debe aplicarse un enfoque basado en los derechos humanos.

(Onusida 2009, p. 6)

\section{Introducción}

El trabajo sexual por las actividades propias de su ejercicio, expone a quienes lo practican a riesgos de todo tipo, como la violencia en sus diversas manifestaciones, afectaciones psicológicas por el estigma social e infecciones de transmisión sexual (ITS) y virus de inmunodeficiencia humana (VIH).

En este contexto, la discriminación perjudica especialmente a las mujeres profesionales del sexo por cuenta de los mandatos de género en los que lo masculino subordina a lo femenino en aspectos económicos, políticos, culturales y sociales.

La situación de las mujeres y niñas en el escenario internacional, facilita las condiciones para que el trabajo sexual sea en su mayor parte desempeñado por este grupo poblacional, ya que como lo señala el Programa Conjunto de las Naciones Unidas sobre el VIH/sida (Onusida) (2009), el acceso desigual por género a la educación, al empleo y al crédito entre otros factores, reduce las escasas opciones disponibles, sobre todo para las mujeres.

Desde esta perspectiva que reconoce la vulneración de los derechos de las mujeres que se dedican al trabajo sexual, los organismos internacionales y las organizaciones no gubernamentales, admitieron la necesidad de promocionar los servicios de apoyo y atención a las trabajadoras del sexo, aunque desconocieron al cliente, según Yaibhé (2008) por las normas tradicionales que dejan de lado la responsabilidad de los hombres sobre las consecuencias del sexo y la sexualidad (Tirado, 2011a).

La atención que se presta a las enfermedades de transmisión sexual (ETS) en relación con el trabajo sexual no es algo nuevo, siendo el VIH el problema más reciente desde la visión médica atada a discursos y prácticas morales sobre el uso del cuerpo como una actividad económica.

Desde la aparición de la pandemia del VIH/sida en el mundo hace más de 30 años, la atención se ha centrado en contrarrestar los efectos de quienes padecen de esta enfermedad así como en la prevención de su contagio, sin embargo, el reconocer los riesgos de la actividad sexual de los profesionales del sexo no ha representado en todos los casos un avance en el conocimiento acerca de la prevención, tratamiento y atención, sino que ha gestado discursos médico-legales en torno al trabajo sexual que dificultan una visión integral del fenómeno.

El anterior panorama problemático y de intervención a estas realidades de enfermedades e infecciones, tratamiento, estigmatización y reivindicación de derechos, mediante la conjugación de diferentes postulados de científicos e instituciones especializadas, permite no solo visibilizar falencias y excesos sino construir propositiva y preventivamente, por tanto, esta reflexión articula el método histórico, dialéctico y la revisión documental.

El concepto de trabajo sexual que se usa en el presente escrito, supone un debate bastante extenso sobre la forma en la que se debe asumir desde la sociedad este evento, ya sea como una actividad que debe desaparecer o que se debe resignificar con base en su comparación con trabajos que tienen en materia de derechos cobertura total en lo que respecta al derecho laboral.

En este artículo se retoma el concepto de trabajo sexual en oposición al de prostitución y/o persona en situación de prostitución, siguiendo el desarrollo y lógica expuesta por la Corte Constitucional colombiana en su sentencia T-629 de 2010, en donde se considera como un trabajo siempre y cuando se realice con el to- 
tal consentimiento de la persona que lo ejecuta. Así mismo, se separa del concepto de trata de personas con fines de explotación sexual, fenómeno que contraría los principios de libertad y acción de las víctimas de este flagelo.

\section{Discursos médico-legales frente al trabajo sexual}

En la época de los antiguos romanos (Overs \& Longo, 1997) se restringían los burdeles a zonas especiales como respuesta a las discusiones que se asemejan a las que aún se dan sobre el control del fenómeno del trabajo sexual, remitiéndose a un plano moral.

La relación entre las ITS y el trabajo sexual se comenzó a percibir como un problema de salud desde el siglo XIX, periodo que coincide, por lo menos en Europa, con un ejercicio severo de poder sobre el cuerpo, por medio de discursos moralistas que en la marca de la prohibición grabó la corporalidad del cuerpo, especialmente el de las mujeres.

Foucault (1977) lo evidenció ampliamente al reconocer que a partir del siglo XVIII el peso del poder se ejerció sobre la constitución propia de los cuerpos, moldeándolos y reprimiéndolos de acuerdo con los discursos morales esparcidos sobre el tejido social, tocando ámbitos como la familia, el Estado e, incluso, espacios científicos como el médico que abanderó el proceso de construcción del deber ser del cuerpo, en particular de la corporalidad femenina.

Además, como hubo momentos álgidos de control de la sexualidad en el siglo XX, debido a las mejoras en el conocimiento de las ITS, la mirada más liberal sobre el cuerpo y la sexualidad, disminuyó los dispositivos de control del cuerpo, sin embargo, como lo señala Overs y Longo (1997), la aparición del VIH marcó una nueva etapa de control que a su vez repercute en las sociedades sobre su percepción de cómo manejar esta pandemia, encontrando en el trabajo sexual un foco de transmisión que apunta directamente responsabilidades a quienes practican esta actividad.

Cuando el VIH se identificó por primera vez, quienes se señalaron de inmediato como culpables fueron los trabajadores del sexo, siendo portadores potenciales de una enfermedad fatal. Este señalamiento produjo efectos sociales -que no en todos los casos fueron positivos- en las personas vinculadas al trabajo sexual, "se desarrollaron respuestas de diferentes proporciones alrededor del mundo, desde medidas represivas hasta movilizaciones eficaces de la comunidad y programas de salud pública" (Overs \& Longo, 1997, p. 4).

En el siglo XIX para el caso colombiano, los discursos hegemónicos sobre los que se cimentaron las prácticas sexuales surgieron desde la ciencia médica. La prostitución fue juzgada como un mal inevitable, un cáncer social y una enfermedad de la sociedad, por ello se luchó para combatirla y erradicarla (Obregón, 2002).

A finales del siglo XIX se crea en Colombia la Junta Central de Higiene (JCH), en la cual "los médicos dispusieron de las bases institucionales para desplegar su labor no solamente curativa y sanitaria, sino también social y moral que les permitía diagnosticar los males de una sociedad en franco proceso de urbanización y de cambio" (Obregón, 2002, p. 162).

La prostitución se percibió desde dos ángulos, por una parte, era una actividad que atentaba contra el pudoroso y tradicional uso del cuerpo, discurso recurrente en la moral cristiana. Por otra, se sustentó su abolición desde la concepción del riesgo de la actividad sexual remunerada al ser un vehículo de ETS.

La disertación médica como soporte del conocimiento científico legitimó los postulados legales, como lo mostraba el Código Penal de la República de 1858, en el cual se prohibía la prostitución, además de vedar la entrada de personas con ETS a hospitales de caridad (Obregón, 2002). 
Entrado el siglo XX, las transformaciones industriales en el país gestaron cambios en la composición urbano/rural. Estos cambios condujeron a un crecimiento poblacional de las ciudades, que en el caso de Bogotá fue significativo. Según Obregón (2002), entre 1870 y 1895 la ciudad pasó de tener 40.883 habitantes a 95.813, provenientes de zonas rurales.

En este contexto de industrialización la mano de obra proveniente de regiones rurales fue empleada en labores de baja calificación, impulsando el crecimiento desbocado de la capital de la nación.

El trabajo sexual en el caso de Bogotá a comienzos del siglo XX aumentó con el incremento poblacional, situándose en el centro de la ciudad en donde se desarrollaba la actividad comercial de la ciudad.

En 1914, se da inicio al control y no a la prohibición por cuenta de la crecimiento poblacional que condujo a un control sanitario creando juntas de salubridad y policía para atender y curar a las personas que sufrían de enfermedades venéreas o sifilíticas (Guzmán, 2012).

En ese momento, se creó en Bogotá un control de quienes ejercían el trabajo sexual mediante un certificado en el que constaba su estado de salud con una fecha de expiración, y en caso de que en el examen se encontrara alguna enfermedad se debería atender al paciente hasta su total curación.

Para comienzos del siglo XX, los médicos que trataban las enfermedades venéreas adoptaron una perspectiva que les permitía establecer -no solo comprender- el fenómeno desde su visión médica, además determinaron las conexiones con problemáticas sociales, económicas y educativas. Se combatieron principalmente tres flagelos sociales que fueron relacionados con la actividad sexual remunerada: el alcoholismo, la sífilis y la tuberculosis.
El reconocimiento de un contexto que difícilmente se podría negar, llevó a que se tomaran medidas que hicieran posible contrarrestar lo que para la ciencia médica se producía a causa del desborde del fenómeno de la prostitución.

El Tercer Congreso Médico Nacional, que se reunió en Cartagena en 1918, recomendó la reglamentación de la prostitución de acuerdo con las necesidades regionales, el establecimiento de dispensarios gratuitos, la visita semanal a las prostitutas para hospitalizar a quienes resultaren enfermas o sospechosas y la divulgación, en los establecimientos de segunda enseñanza, de los peligros de los enlaces con personas contaminadas de enfermedades 'venéreas' (Obregón, 2002, p. 173).

La instauración de patrones regulares en sus pacientes, les facilitó a los médicos construir un discurso que controlaba el modelo de sociedad en un momento de la vida nacional intervenido por la iglesia católica, que a su vez se erigía como fundamento de la constitución del orden social en la nación, época conocida como La Regeneración.

En este escenario, según datos de la época, se calculaba que el $35 \%$ de las $2.500 \mathrm{mu}$ jeres que ejercían el trabajo sexual en la ciudad, tenía alguna ETS (Obregón, 2002). Para principios del siglo $\mathrm{XX}$, en pleno desarrollo industrial de Colombia, parecía inevitable evadir un fenómeno que se propagaba al ritmo que las ciudades del país crecían sin orden ni concierto.

El gobierno, para hacer frente al aumento de las ETS creó el Instituto de Higiene Social de Cundinamarca, encargado de la lucha antivenérea. Al mismo tiempo, se concibió el Hospital Universitario de la Samaritana, que llevó el nombre que marcaba la visión de la moral cristiana imperante de aquella mujer que de acuerdo con el relato bíblico se "regeneró" tras haber mantenido una vida pública, culpabilizando a la 
mujer de las ETS y excluyendo las responsabilidades de los hombres.

La visión moralista reinante en la sociedad de la época, acusó a las mujeres tanto por los problemas de salud pública como por los atentados a las buenas costumbres, siendo esta última falta la que más se atacó después de haberse descubierto las propiedades de la penicilina, medicamento que combatió eficazmente las ITS, por lo que la reglamentación ya en la década de los cuarenta era innecesaria y se criminalizó la actividad sexual remunerada.

En el caso de otras ciudades de Suramérica como Buenos Aires, abriendo el siglo XX, el escenario no era muy diferente. Las mujeres que se dedicaban al trabajo sexual se consideraban un mal para la sociedad, desestimando el papel de los clientes (Obregón, 2002).

Así mismo, se consideró que las mujeres dedicadas a esta actividad eran la principal fuente de transmisión de ITS a sus clientes, enfocando las regulaciones y el tratamiento médico a estas e ignorando a hombres dedicados al trabajo sexual (Guy, 1991).

Desde finales del siglo XX, con la reivindicación y apertura progresiva de los espacios y derechos de la mujer -como la lucha sobre los derechos sexuales y reproductivos y la aparición de asociaciones de mujeres trabajadoras del sexo-, se ha logrado centrar un conocimiento sobre los riesgos de las ITS y el VIH desde una perspectiva integral que no sostiene discursos que legitimaron el estigma y la discriminación sobre las profesionales del sexo.

\section{El estigma: derechos en suspenso}

El estigma que se asocia a las personas que ofrecen servicios sexuales es la forma en que se marcan diferencias con lo que socialmente se erige como normal.
Un individuo que podía haber sido fácilmente aceptado en un intercambio social corriente posee un rasgo que puede imponerse por la fuerza a nuestra atención y que nos lleva a alejarnos de él cuando lo encontramos, anulando el llamado que nos hacen sus restantes atributos (Goffman, 2006, p. 15).

Es así, que entre los problemas que más han perjudicado las condiciones de las personas vinculadas a la prestación de servicios sexuales remunerados, está la estigmatización que se asocia al uso del cuerpo (sobre todo de los órganos sexuales) como principal fuente de generación de ingresos.

La estigmatización presente en el trabajo sexual tiene una carga especial para las mujeres que lo ejercen. Sumado a los mandatos de género que reprimen a la mujer y en particular su sexualidad, realizar una actividad económica que se basa en el uso del cuerpo es una condición que se ha legitimado como fuente de deshonra para las mujeres trabajadoras sexuales.

Los discursos mediante los cuales se acepta y promueve la represión y su consecuente coacción social, se sostienen desde instituciones sociales como la religión, que bajo la égida de la figura de la "buena" mujer, ha creado imaginarios en los que se marca una ética del cuerpo. Así como a los hombres, desde una perspectiva heteronormativa, se les han asignado roles en los que deben mantener sus prácticas demostrativas de virilidad y masculinidad que se ponen en duda en el caso de trabajadores sexuales varones y transgénero.

Es así como en el contexto del trabajo sexual, quienes ofrecen servicios sexuales tienen etiquetas que los enmarcan y que a su vez los diferencian entre sí, y que socialmente se reproducen como dispositivos de poder y dominación basandose en los estereotipos o creencias sobre el uso del cuerpo, especialmente el de la mujer. 
Según Dolores Juliano, en entrevista realizada por Muez (20 de octubre de 2003), "Por el hecho de dedicarse a ello [trabajo sexual] la sociedad considera normal privarles [a las trabajadoras sexuales] de determinados derechos, se les desvaloriza como personas y ese prejuicio las estigmatiza" (p. 1). Es posible que esta condición sea uno de los factores principales que repercute en otros fenómenos asociados al trabajo sexual, como los vacíos en la información y el acceso a servicios de salud.

En específico, el acceso a la salud por parte de las trabajadoras sexuales se liga al proceso de estigmatización, como lo demuestran Amaya, Canaval y Viáfara (2005) al afirmar que

Sentirse estigmatizada por realizar el oficio de trabajadora sexual implica para las mujeres que lo ejercen el verse en condiciones diferentes a las demás personas, lo cual podría ser un factor que dificulta la consulta a los servicios de salud por motivos distintos a los de obtener un certificado de salud que les permita desempeñarse en el oficio (p. 73).

Las personas que se dedican a la venta de servicios sexuales, aparte de las difíciles condiciones de su trabajo, enfrentan a diario el rechazo de sus propias comunidades o de las que los reciben. Junto con esto, se debe subrayar el maltrato recibido por clientes y proveedores de servicios. Según la Onusida (2009) entre los elementos que se asocian a la estigmatización de los trabajadores sexuales están:

El rechazo de sus comunidades cuando se ejerce el trabajo sexual en su lugar de origen. En caso de ejercer en otros lugares, están expuestos a ser expulsados, castigados con violencia sexual o física, además de estar expuestos a que confisquen sus pertenencias.

Cuando quien ejerce el trabajo sexual ha dejado su comunidad a temprana edad, encuentra dificultades para reintegrarse tanto a sus familias como a sus redes sociales.

Las personas que se dedican al trabajo sexual, probablemente puedan sufrir de desaprobación de la comunidad o la violencia de parte de esposos, parejas o familiares.

Los hijos de personas dedicadas al trabajo sexual también pueden ser objeto de la estigmatización, afectando sus derechos de acceso a la educación y atención de la salud (p. 17).

Otra dificultad que afrontan quienes se dedican al trabajo sexual, es la vulneración sus derechos, entre estos, el acceso a la salud, lo que obstaculiza la prevención, tratamiento, atención y apoyo a ITS y VIH.

Por cuenta de la estigmatización que tiene la actividad sexual remunerada, la falta de acceso a servicios de salud, como a otras garantías que se ofrecen en demás actividades laborales, entorpece las posibilidades de que se garanticen los derechos de esta población.

Según Muez (20 de octubre de 2003), el trabajo sexual desde el punto de vista laboral, no es peor que otros oficios que se pueden ejercer con escasa formación o posibilidades laborales, sin embargo, las situaciones que se presentan en esta actividad, que se vinculan a la estigmatización, producen efectos adversos en todo sentido para quien decide practicarla.

De acuerdo con Onusida (2009), para reducir el estigma y las prácticas discriminatorias, son necesarias acciones integrales como intervenciones comunitarias específicas, en las que se promueva la inclusión social y el desarrollo de capacidades desde una perspectiva de género. En el marco del apoyo comunitario, debe brindarse ayuda psicosocial para personas que hayan sido víctimas del señalamiento asociado al trabajo sexual. 


\section{VIH/sida e infecciones de transmisión sexual}

El contexto del trabajo sexual implica riesgos como la violencia del medio - la afrenta de la cual pueden ser víctimas-, el consumo de estupefacientes y alcohol, entre otros, así como el contagio de ITS y VIH/sida.

Este último riesgo recibe atención primordial por las cifras alarmantes de contagios que crecen a diario, no solo en el trabajo sexual. La Organización Mundial de la Salud (OMS) en 2004 estimaba que en el mundo se producían aproximadamente 340 millones de nuevos episodios de ITS curables, situación preocupante si se tiene en cuenta que la mayoría de estas enfermedades es asintomática -especialmente en mujeres-, además de ser un facilitador en la transmisión del VIH/sida (Romero, Rojas, Ballesteros, Clavo \& Menéndez, 2004).

El contagio de este tipo de enfermedades se concentra en algunas regiones como el sudeste asiático y en el África subsahariana, aunque en otras zonas se ha logrado establecer un aumento sustancial, sobre todo en hombres que practican sexo con hombres.

A pesar del incremento significativo en diferentes latitudes, es en los países en desarrollo en donde se presenta el mayor nivel de vulnerabilidad frente al contagio de estas enfermedades. Según información de Onusida y OMS (1997):

En muchos países en desarrollo las ITS figuran desde hace varias décadas entre las cinco principales enfermedades para las cuales los adultos tratan de obtener servicios de asistencia sanitaria. Rara vez se cuenta con mecanismos de vigilancia confiables, y es frecuente que no se conozca la magnitud exacta del problema (p. 6).

Según datos del informe que presentaron Onusida y OMS (1997), hace más de una década habían sido registrados en el mundo 340 millones de ETS curables. La distribución por enfermedad es la que presenta la tabla 1.

Tabla 1

Estimaciones de casos anuales de enfermedades de transmisión sexual curables, en todo el mundo, 1995

\begin{tabular}{lc}
\multicolumn{1}{|c}{ Enfermedad } & Nuevos casos (millones) \\
\hline Blenorragia & 62 \\
Clamidiosis & 89 \\
Sífilis & 12 \\
Chancro blando & 7 \\
Tricomoniasis & 170 \\
Total & $\mathbf{3 4 0}$
\end{tabular}

Fuente: Romero et al., 2004, p. 6.

La enfermedad que más casos registró fue la tricomoniasis con 170 millones de individuos con la infección, seguida de la clamidiosis con 89 millones de personas infectadas. De acuerdo con la distribución de las enfermedades por región, siguen siendo los países en desarrollo en donde se da el mayor número de nuevos casos de contagio de ETS. África meridional y sudoriental es el territorio con más alto porcentaje de nuevos casos de ETS, seguido de África subsahariana y América Latina y el Caribe. 
Tabla 2

Estimaciones de nuevos casos anuales de enfermedades de transmisión sexual curables (excluido el chancro blando) en el grupo de población entre 15 años y 49 años de edad, en todo el mundo, 1995

\begin{tabular}{|c|c|c|}
\hline Región & $\begin{array}{c}\text { Total de nuevos casos por año } \\
\text { (por mil) }\end{array}$ & $\begin{array}{c}\text { Incidencia por mil entre los } 15 \text { años } \\
\text { y los } 49 \text { años de edad }\end{array}$ \\
\hline Estados Unidos y Canadá & 14.000 & 91 \\
\hline América Latina y el Caribe & 36.000 & 145 \\
\hline Europa occidental & 16.000 & 77 \\
\hline Europa oriental y Asia central & 18.000 & 112 \\
\hline Asia oriental y el Pacífico & 23.000 & 28 \\
\hline Asia meridional y sudoriental & 150.000 & 160 \\
\hline Australasia & 1.000 & 91 \\
\hline África del Norte y Oriente Medio & 10.000 & 60 \\
\hline África subsahariana & 65.000 & 254 \\
\hline Total & 333.000 & 1018 \\
\hline
\end{tabular}

Fuente: Romero et al., 2004, p. 7.

Los datos de las infecciones del VIH/sida, según la Onusida y la OMS en el 2007, indican que para ese año se registraban 33,3 millones de personas viviendo con $\mathrm{VIH} /$ sida, de los cuales 30,8 millones eran mayores de edad y 2,5 millones menores.

Del total de individuos que para el 2007 vivían con $\mathrm{VIH} /$ sida, 15,4 millones correspondía a mujeres y el restante 17,8 millones a hombres. La expansión del VIH/sida en el mundo es alarmante ya que "Cada día, más de 6.800 personas contraen infección por el VIH y más de 5.700 fallecen a causa del sida [...]" (Onusida \& OMS, 2007, p. 4).

En el informe de Onusida de 2012, se registraban 35 millones de personas en el mundo viviendo con VIH, lo que representa un aumento de 1,8 millones de nuevos casos en el periodo de los informes de Onusida (2007-2012).
La situación en algunas regiones del planeta es preocupante, debido a la ampliación del número de nuevas infecciones en Oriente Medio y África septentrional, así como por el incremento de las mismas en Europa oriental y Asia central después de haber permanecido las tendencias estables antes de la entrada al nuevo siglo.

No obstante el aumento de las personas con VIH, los avances en su lucha han demostrado su eficiencia en la disminución de las nuevas infecciones en algunas regiones. Según Onusida (2012), el número de personas que se infectaron por el VIH en 2011 fue un 20 $\%$ menor que en 2001, especialmente en zonas del Caribe y África subsahariana.

La cifra de personas que muere por causa del VIH en 2011 fue de 1,7 millones, $24 \%$ menos muertes que en el 2001, descenso que se debe a la extensión de la terapia antirretroviral y a la reducción de la incidencia del VIH desde su punto máximo en 1997 (Onusida, 2012). 


\section{Trabajo sexual, infecciones de trans- misión sexual y virus de inmunodefi- ciencia humana}

En el ámbito del trabajo sexual, se ha conseguido probar un riesgo elevado de contraer ITS y VIH, dada la constante exposición a la que se encuentran quienes lo ejercen por su alta actividad sexual. Como se ha podido determinar en estudios (Romero et al., 2004), la prevalencia más elevada de contraer ITS es en el grupo de trabajadoras sexuales.

En el estudio de Romero et al. (2004) a un grupo de 400 personas de diferentes ocupaciones en Bangladés, se constató que el caso más alto de sífilis se daba en el grupo de trabajadoras sexuales con el 56,8 \%. En Canadá se encontró una prevalencia de ITS de mujeres trabajadoras sexuales del $10 \%$.

En otras investigaciones, como la de Yaibhé (2008), se afirma que en algunas zonas de África los índices de infección de VIH entre trabajadores sexuales pueden llegar al $60 \%$, así como "en los países occidentales, la tasa de infección en VIH/sida entre los trabajadores sexuales que usan drogas, trabajadores sexuales masculinos urbanos y transgénero son más altas que el promedio" (Yaibhé, 2008, p. 15).

A pesar de estos datos, no se ha podido establecer que los trabajadores del sexo sean relevantes en la expansión del VIH en el resto de la población. Como lo asevera Yaibhé (2008) "en Canadá, China, Austria, Australia y Alemania, las tasas en los trabajadores sexuales son más bajas que en grupos comparables de no trabajadores sexuales" (p. 15).

Así como no hay datos que demuestren que en el trabajo sexual la transmisión del VIH a clientes sea un riesgo de mayor importancia que en otros sectores poblacionales, lo que no significa que no sea necesario que se realicen estudios y programas de prevención a este sector. En la misma vía, en el estudio realizado por Amaya et al. (2005), se asegura que la incidencia por VIH entre las trabajadoras sexuales es igual que el de las mujeres que se dedican a otras actividades.

Por su parte, Zúñiga y Tepichín (2000), consideran que es común que se sobrestime el riesgo real de la infección por el VIH a partir de las personas dedicadas al trabajo sexual, ya que las investigaciones que se han hecho generalmente se elaboran con población de recursos económicos escasos, dejando de lado un sector de la población amplio que no se toma en cuenta.

Concebir a las personas dedicadas al sexo comercial como un foco de transmisión de ITS y VIH es socialmente más aceptable que admitir que existen otras dinámicas y prácticas como la transmisión por relaciones homosexuales o el consumo de drogas intravenosas.

El estigma asociado tanto a quienes prestan los servicios sexuales como a quienes los demandan, se convierte en uno de los principales problemas en la lucha contra las ITS, ya que relegar la actividad a un plano de lo prohibitivo, impulsa a la clandestinidad que no puede redundar en beneficios para la población (Tirado, 2010).

Desde este enfoque, es necesario analizar más a fondo la relación entre trabajo sexual y ITS/VIH que apunte a la prevención y tratamiento y no a la reproducción de discursos como el médico o el jurídico, que en algunos casos siguen estigmatizando a las personas dedicadas al sexo remunerado.

Si bien la transmisión de ITS y VIH en el mundo sigue en progreso, especialmente en países en desarrollo, no se puede decir que el trabajo sexual sea la principal causa, aunque no se deben dejar de lado programas de prevención y atención a este sector altamente vulnerable, que por una parte se expone a la transmisión de ITS y VIH y, por otra, es foco de especulaciones que refuerzan los prejuicios y el señalamiento. 
La comprensión del fenómeno desde una visión integral reconoce los derechos de las poblaciones estigmatizadas, como lo han sido las trabajadoras sexuales. Instituciones como la Onusida, perciben el trabajo sexual como una actividad económica quitando el peso del tradicional estigma asociado a este oficio.

En términos de la Onusida (2009) "los profesionales del sexo son aquellos adultos mujeres, varones y transexuales, y jóvenes que reciben dinero o mercancías a cambio de servicios sexuales, ya sea en forma habitual $u$ ocasional" (p. 3), incluyendo en su definición a sectores poblacionales de diversa composición y ubicación.

Aquí se asume el trabajo sexual desde el derecho humano a la libertad y la seguridad de la persona con el conocimiento propio del control de su cuerpo y sexualidad, así como el derecho a no ser víctima de trata de personas.

Según la Nota de orientación de la Onusida sobre el VIH y el trabajo sexual (2009), este fenómeno es diferente entre y dentro de los países e incluso de las comunidades. El trabajo sexual varía de acuerdo con su grado de informalidad y va hasta redes complejas, la forma en que se establecen las condiciones de acceso al servicio sexual y la negociación, entre otros factores.

Así mismo, es claro para la Onusida (2009) que muchas personas que cambian servicios sexuales por alguna remuneración no se identifican como trabajadores sexuales y a su vez, no buscan asesoramiento o servicios de prevención, atención y apoyo con relación especial al VIH destinados a las personas que se dedican a esta actividad económica. En muchos casos, los profesionales del sexo oscilan en límites estrechos marcados por la libre elección y el trabajo sexual forzado.

En el marco del trabajo sexual y la situación de particular vulnerabilidad en la que se halla quien lo desarrolla, las ITS y el VIH/ sida son un riesgo tanto para los trabajadores sexuales como para sus clientes, riesgo que debe ser abordado por las instituciones. Aunque en la actualidad, no se sabe con certeza el número de trabajadores sexuales que trabajan con alguna ETS, existe la suficiente información (Overs \& Longo, 1997) como para realizar servicios de apoyo efectivos a la población trabajadora sexual.

Los patrones que se han establecido en el estudio del VIH/sida y las ITS (Owers \& Longo, 1997) prueban que existe alta vulnerabilidad cuando existe un acceso limitado a preservativos, escasa información sobre las enfermedades, poco respeto a los derechos civiles y pobreza.

Entre la población con alta vulnerabilidad debido a los factores en mención, se encuentran hombres y mujeres jóvenes sin educación, personas transgénero $\mathrm{y}$ migrantes a nuevos países o ciudades.

Aunque, como ya se dijo, no se puede determinar una relación directa entre el aumento de nuevos casos de contagio de ITS y VIH y la actividad del sexo comercial, sí existen factores que acrecientan el riesgo de contagio en este oficio. Según Zúñiga y Tepichín (2000) los factores más relevantes son:

1. Tasa de seroprevalencia al VIH existente en el área de procedencia y residencia de las trabajadoras sexuales y clientes. La expansión del VIH en todas las regiones varía de acuerdo [con] diversos factores, así por ejemplo en regiones de África y el Caribe se puede encontrar una seroprevalencia mayor al $80 \%$ entre trabajadores sexuales, mientras en Europa y Estados Unidos el riesgo es por la drogadicción intravenosa asociada al sexo comercial. 
2. Eficiencia de transmisión del VIH en esa población.

3. Mayor número de parejas sexuales.

4. Tipo de prácticas sexuales.

5. Nivel socioeconómico bajo.

6. Nivel de oferta y demanda de la prostitución en cada zona o país.

7. Uso de anticonceptivos hormonales y presencia de otras infecciones de transmisión sexual (ITS).

8. Estigmatización y bajo acceso a servicios de salud o educativos.

9. Asociación con el consumo de alcohol y drogas.

10. Asociación con otras prácticas de riesgo (transfusión, pareja estable infectada, drogadicción intravenosa, etcétera).

11. Poca habilidad para negociar con los clientes medidas preventivas como el preservativo (p. 204).

Los factores vinculados que abren posibilidades de vulnerabilidad frente a las ITS tienen un eje transversal y es la carencia de información, que en el sexo comercial se atribuye tanto a clientes como a trabajadores sexuales.

El acceso a la información referida a la prevención y tratamiento de ITS y VIH en el trabajo sexual, tiene limitaciones, pues no es homogéneo para toda la población, por restricciones presentes que se asocian a la estigmatización de la cual es objeto el trabajo sexual.

Políticas encaminadas a prevención, tratamiento y atención de las ITS y el VIH en clientes y trabajadores sexuales

El conocimiento de las dinámicas en el trabajo sexual permite acercarse a las vulneraciones más frecuentes que ponen en riesgo la protección tanto de quienes ejercen el trabajo sexual como de sus clientes.
Como se ha dicho, el acceso a la información es fundamental para disminuir las contingencias que se ligan al trabajo sexual, por lo que tanto profesionales del sexo como sus clientes deben tener las oportunidades de recibir educación de calidad (Tirado, 2010).

En armonía con Onusida (2009), aunque la educación acerca de la prevención, tratamiento, atención y apoyo con relación al VIH es primordial para mejorar las condiciones tanto de clientes como de trabajadores sexuales, es necesario el diseño de una enseñanza/aprendizaje basada en el diálogo y en enfoques participativos que se acerquen a las circunstancias de la problemática.

Los programas de información se deben apoyar tanto en los conceptos elementales sobre riesgo, prevención, tratamiento y atención del VIH como de salud sexual, derechos, obligaciones, responsabilidades y oportunidades para actuar tanto individual como colectivamente (Onusida, 2009).

Como estrategia de difusión de la información es de gran utilidad, de acuerdo con las recomendaciones de la Onusida (2009), hacer uso de diversos métodos, entre ellos, educación entre pares, asesoramiento por cuenta de los centros de salud, materiales impresos y medios masivos de comunicación que hagan énfasis en los rangos etarios a los que se pretende llegar y respetando las diferencias sexuales.

En el trabajo sexual, los servicios institucionales deben contarconladisponibilidad y accesibilidad para los profesionales del sexo y sus clientes, sin excluir la diversidad sexual y de categorías existentes, lo que supone una distinción de las necesidades de profesionales mujeres, hombres y transexuales desde criterios de equidad que ayuden a identificar problemas particulares.

Frente a la prevención, atención y apoyo al VIH, Onusida (2009) recomienda acciones 
fundamentales que deben redundar en beneficio de los agentes vinculados al trabajo sexual, en especial trabajadores y trabajadoras sexuales y clientes. Entre las recomendaciones esenciales se señala solucionar aquellos obstáculos estructurales como "las políticas, leyes y prácticas consuetudinarias que impiden el acceso y la utilización de los servicios apropiados de prevención, tratamiento, atención y apoyo con relación al VIH” (Onusida, 2009, p. 8).

Se ha indicado que el estigma asociado al trabajo sexual repercute directamente en quienes ofrecen servicios sexuales remunerados, por lo que la prevención, tratamiento, atención y apoyo a las ITS y VIH en el ámbito del trabajo sexual debe partir de un reconocimiento y erradicación de la violencia, abuso y discriminación, posibilitando el acceso a la información primordialmente a los profesionales del sexo.

Reconociendo como indispensable un proceso de sensibilización sobre el trabajo sexual que coadyuve a garantizar mejores condiciones en las que se ejerce el trabajo sexual, Onusida (2009) recomienda como acciones principales a desarrollar en este ámbito:

Políticas y programas que garanticen la erradicación de la violencia, el abuso y la discriminación; información para los profesionales del sexo y sus clientes y otros actores de la industria del sexo; acceso confiable y asequible a artículos necesarios, como preservativos masculinos y femeninos de calidad, lubricantes a base de agua y anticonceptivos; y otros requisitos para la salud, como alimentos, saneamiento y agua potable; acceso a asesoramiento y pruebas voluntarias del VIH, con tratamiento, apoyo social eficaz y atención para los profesionales de sexo con pruebas serológicas positivas de infección por el VIH; acceso a atención primaria de la salud de calidad, tratamiento de la tuberculosis, servicios de salud sexual y reproductiva, especialmente tratamiento de las ITS, y prevención de la transmisión materno infantil; acceso a programas de reducción del daño relacionado con el alcohol y las drogas, por ejemplo, agujas y jeringas estériles y tera- pia de sustitución de opiáceos; integración de los servicios de VIH en todos los servicios de asistencia social pertinentes, incluidos mecanismos de apoyo social para profesionales del sexo y sus familias (pp. 8-9).

Las acciones propuestas deben desarrollarse con base en el ordenamiento jurídico que permita un fundamento legal que proteja los derechos de la población vinculada al trabajo sexual.

Como principio ordenador de las políticas públicas, debe regir la conciencia sobre la vulneración de derechos a la que son expuestos $\mathrm{y}$ expuestas las personas que se dedican a esta actividad, ya que al no reconocerse en la legislación se abren vacíos normativos que niegan la existencia del trabajo sexual y sus implicaciones en las condiciones especiales en las que se desarrolla este oficio (Tirado, 2011b).

Si bien la lucha contra las ITS y el VIH es un esfuerzo que se realiza en la población general, con particular énfasis en comunidades vulnerables y focos probables de infección, desde la creación de políticas y programas se debe mantener una visión integral sobre el trabajo sexual que ayude a mitigar los riesgos tanto de oferentes sexuales remunerados como de clientes.

La visión integral sobre el trabajo sexual debe partir del reconocimiento de las condiciones sociales que se han asignado a quienes practican esta actividad, por lo que la lucha contra la discriminación se convierte en un eje central que posibilita el acceso a la información necesaria para la prevención, tratamiento, atención y apoyo de ITS y el VIH.

La visión integral sobre las condiciones de las y los profesionales del sexo debe darse desde los organismos encargados de legislación, los sistemas de salud y demás dependencias de los gobiernos responsables del diseño, ejecución, vigilancia y evaluación de políticas 
y programas que deben garantizar los derechos de la población.

Además, urge la incorporación en la toma de decisiones de actores clave como organizaciones de trabajo del sexo, de la sociedad civil y de la comunidad en general, admitiendo que sin la participación activa de los profesionales del sexo no se puede tener una perspectiva óptima de las necesidades que se transforman con la rapidez que el trabajo sexual se modifica.

\section{Referencias}

Amaya, A., Canaval, E., \& Viáfara, E. (2005). Estigmatización de las trabajadoras sexuales : influencias en la salud. Colombia Médica, 36(3-Supl 2), 65-74.

Contraloría de Bogotá D.C. (2004). Estudio Sectorial: La prostitución como problemática en el Distrito Capital. Bogotá: Autor.

Foucault, M. (1977). Historia de la Sexualidad (Tomo I, La voluntad de Saber). México: Siglo XXI.

Goffman, I. (2006). El Estigma: La identidad deteriorada. Buenos Aires: Amorrortu.

Guy, D. J. (1991). Sex and danger in Buenos Aires: prostitution, family, and nation in Argentina. Lincoln: University of Nebraska Press.

Guzmán, M. S. (2012). Prostitución y corrupción de menores vista desde el código penal colombiano de 1889 y los códigos de policía de 1886 y 1914. Historia 2.0. Conocimiento Histórico en Clave Digital, 2(1), 26-36. Recuperado de http://dialnet.unirioja.es/servlet/articulo?codigo $=3958332$

Muez, M. (20 de octubre de 2003). Entrevista a Dolores Juliano: El estigma es el principal problema de la prostitución. Elpaís. Recuperado de elpais.com/diario/2003/10/20/ paisvasco/1066678810_850215.html

Obregón, D. (2002). Médicos, prostitución y enfermedades venéreas en Colombia (1886-1951). História, Ciências, Saúde - Manguinhos, 9, 161-186.

ONUSIDA, \& OMS. (1997). Enfermedades de transmisión sexual: políticas y principios de prevención y asistencia. Recuperado de http://whqlibdoc.who.int/hq/1997/ ONUSIDA_OMS_97.6_spa.pdf?ua=1

ONUSIDA, \& OMS (2007). Situación de la epidemia de Sida. Recuperado de http://data. unaids.org/pub/EPISlides/2007/2007_epiu pdate_es.pdf

ONUSIDA, Unicef, \& OMS. (2013). Presentación de informes sobre los avances en la respuesta mundial al sida 2013: Desarrollo de indicadores básicos para el seguimiento de la Declaración política de las Naciones Unidas sobre el VIHy el sida de 2011. Ginebra: ONUSIDA.

ONUSIDA. (2009). Nota de orientación del ONUSIDA sobre el VIH y el trabajo sexual. Suiza. Recuperado de http://www. unaids.org/en/media/unaids/contentassets/dataimport/pub/basedocument/2009/ jc1696_guidance_note_hiv_and_sexwork es.pdf

ONUSIDA. (2012). Informe mundial de ONUSIDA sobre la epidemia mundial de SIDA. Recuperado de http://www.unaids.org/ en/media/unaids/contentassets/documents/ epidemiology/2012/gr2012/20121120_ UNAIDS_Global_Report_2012_with_annexes_es.pdf

Overs, C., \& Longo, P. (1997). Haciendo el trabajo sexual seguro. Londres: Russel Press. 
Romero, J., Rojas, D., Ballesteros, J., Clavo, P., \& Menéndez, P. (2004). Prostitución: un colectivo de riesgo. JANO, 67(1544), 106-111.

Tirado, M. (2010). Comercio Sexual. Una mirada desde la sociología jurídica. Lima: Fundación FEFSA-; Instituto Internacional de Derecho y Sociedad -IIDS.

Tirado, M. (2011a). El Debate entre prostitución y Trabajo Sexual. Una mirada desde lo socio-jurídico y la política pública. $R e$ vista de Relaciones Internacionales, Estrategia y Seguridad, 6(1), 127-148.

Tirado, M. (2011b). Implicações do Trabalho Sexual como atividade legalmente re- conhecida: Umacercamentoaotrabalho sexual desde suasdimensões sociológicas e económicas. Revista Prolegómenos Derechos y Valores, 14(27), 247-263.

Yaibhé, N. (2008). Percepción de riesgo de ITS de mujeres adultas en contextos de no exclusividad sexual: un estudio a partir de biografias sexuales (Tesis de maestría). Facultad Latinoamericana de Ciencias Sociales -[FLACSO], México.

Zúñiga, P., \& Tepichín, G. (2000). Sexo comercial e infecciones de transmisión sexual (ITS) en la Ciudad de México. Papeles de Población, 6(23), 203-219. Recuperado de http://www.redalyc.org/ pdf/112/11202309.pdf 